\title{
QUANTIFICATION OF MATCH INTERNAL LOAD AND ITS RELATIONSHIP WITH PHYSICAL FITNESS AND RECOVERY STATE OF PROFESSIONAL SOCCER ATHLETES DURING THE COMPETITIVE PERIOD
}

original paper

() University School of Physical Education in Wroclaw

DOI: https://doi.org/10.5114/hm.2018.76077

\section{LUIZ FERNANDO NOVACK, GISLAINE CRISTINA DE SOUZA, JUAN HENRIQUE SZYMCZAK CONDE, RAFAEL OCTAVIANO DE SOUZA, RAUL OSIECKI}

Department of Physical Education, Federal University of Paraná, Curitiba, Brazil

\begin{abstract} higher strain in the season; however, they recover faster between games.

Key words: perceived exertion, aerobic fitness, creatine kinase

\section{Introduction}

Soccer is a predominantly aerobic sport, with high physical demand, involving high intensity actions (runs at different intensity levels, constant changes of direction, tackles, and jumps) performed repeatedly with short intervals for recovery [1]. Therefore, the control of the workload during matches and training is important. One of the methods most used and widely accepted by soccer clubs and the scientific community is the control of the internal load by the training impulse of the rating of perceived exertion (RPE-TRIMP) [2-5]. This method is based on multiplying the session RPE by the duration of the match or training (time in minutes), allowing the control of the internal load and prescription of the intensity and volume of training throughout the season.
\end{abstract}

Purpose. The aim of the study was to determine the level of physical fitness, internal load, and recovery regarding 5 consecutive official professional soccer games and to correlate the physical fitness with the internal load and recovery variables.

Methods. The total of 11 male professional soccer athletes performed an incremental treadmill test, which allowed to assess their physical fitness, and then participated in 5 official soccer matches held within $8.3 \pm 3.7$ days. After each match, the perceived recovery, perceived muscle soreness, creatine kinase concentration, and session rating of perceived exertion were registered. The effect of the 5 consecutive games was tested with the repeated measures ANOVA and the correlations were examined with the Spearman coefficient. The significance level was set at $p<0.05$.

Results. The internal load and recovery variables were similar throughout the games $(p>0.05)$. Significant correlations were found between internal load and physical fitness $(\rho=0.66)$ and between strain and recovery $(\rho=-0.61)$.

Conclusions. The results suggest that soccer athletes with better aerobic fitness weary more during the game and present

To meet the physical demands of the game, it is important to have a high level of physical fitness. Manzi et al. [6] demonstrated that soccer athletes, during the in-season, present maximal oxygen uptake $\left(\mathrm{VO}_{2 \max }\right)$ of $59.2 \pm 4.3 \mathrm{~mL} \cdot \mathrm{min}^{-1} \cdot \mathrm{kg}^{-1}$ and anaerobic threshold at $86.1 \pm 2.9 \% \mathrm{VO}_{2 \max }$. Moreover, the authors found significant associations between the indicators of physical fitness and the distance covered above 20, 35 , and $55 \mathrm{~W} \cdot \mathrm{kg}^{-1}$ during a soccer match. However, besides the physical fitness, the recovery of the athletes between the games has worried the technical commissions and researchers, since the schedule of games at the professional level is very demanding and normally the athletes participate in games every 2 or 3 days [7]. In this context, clubs usually maintain in their postmatch evaluation routine the measurement of muscle recovery indicators, such as muscle damage biomark-

Correspondence address: Juan Henrique Szymczak Conde, Department of Physical Education, Federal University of Paraná, Coração de Maria Street, 92. Jardim Botânico, Curitiba, Paraná, Brazil, 80210-132, e-mail: juanufpr@gmail.com

Received: March 9, 2017

Accepted for publication: October 23, 2017

Citation: Novack LF, De Souza GC, Szymczak Conde JH, De Souza RO, Osiecki R. Quantification of match internal load and its relationship with physical fitness and recovery state of professional soccer athletes during the competitive period. Hum Mov. 2018;19(3):30-37; doi: https://doi.org/10.5114/hm.2018.76077. 
ers (usually creatine kinase [CK], owing to its practicality) or performance tests (vertical jump) [8], and the use of perceived recovery $(\mathrm{PR})$ and perceived pain scales.

Aquino et al. [9] demonstrated strong correlations between the $\% \Delta \mathrm{CK}$ before and after a soccer match and the number of sprints performed during the match, which supports the use of this enzyme as an indicator of skeletal muscle fibre damage [10]. In addition, studies have proved significant correlations between CK and recovery in athletes $[11,12]$. In this regard, PR scales have been widely used as indirect indicators of the recovery status of athletes [11, 13, 14]. The measurement of PR and pain, summed to biochemical and internal load (RPE-TRIMP) variables, can serve to support interventions that reduce pain and increase recovery efficiency [15], to indicate injury risk [16], and even to suggest the selection of a reserve player to the next game.

Some studies demonstrated correlations between the level of physical fitness and the recovery capacity after exercise [17, 18]. Although these works focused on the acute recovery, measured by the heart rate (HR) and oxygen uptake $\left(\mathrm{VO}_{2}\right)$, their outcomes are relevant, including for soccer. Accordingly, the aim of the study was to determine the level of physical fitness, internal load, and recovery regarding 5 consecutive official professional soccer games and to correlate the physical fitness with the internal load and recovery variables. Our hypothesis was that the response magnitude of the internal load would be similar between the games and the response would be associated with the variables of physical fitness and recovery status after a soccer match.

\section{Material and methods}

\section{Participants}

The total of 11 male Brazilian professional soccer players (age: $26.8 \pm 4.8$ years, body mass: $77.1 \pm 7.1 \mathrm{~kg}$, height: $177 \pm 6 \mathrm{~cm}$, body fat: $8.2 \pm 1.8 \%$, and $\mathrm{VO}_{2 \max }$ : $57.7 \pm 4.3 \mathrm{~mL} \cdot \mathrm{min}^{-1} \cdot \mathrm{kg}^{-1}$ ) from a $1^{\text {st }}$ division Brazilian league soccer club took part in the study. The subjects were all outfield players (goalkeepers were excluded from the study). In addition, not all the players participated in all matches. The study was carried out during the pre-season and beginning of the season of the $1^{\text {st }}$ division of the Paraná Championship (regional level) in 2016. All participants were informed about the study procedures.

\section{Experimental design}

Initially, the participants visited the laboratory; anthropometric variables were measured and fat percentage was estimated on the basis of 7 skinfolds measurement as indicated by Jackson and Pollock [19]. Then, the athletes performed an incremental test on a treadmill (Micromed, Centurion 300, Brasília, Brazil) for the determination of $\mathrm{VO}_{2 \max }$ and ventilatory threshold (VT). One week later, they played 5 official matches within the Paraná Championship with intervals of 8.3 \pm 3.7 days between them. At the end of each match, the time that each athlete effectively played was determined (duration) and the session RPE was registered 30 minutes after the match for quantification of internal load. Forty hours after each match, the athletes returned to the laboratory. In these visits, PR and the perceived muscle soreness (PMS) were registered. Immediately after that, blood CK concentration was examined and the Quick Recovery Test (QRT) was performed. The participants maintained their training program during the entire experimental period, except in the last 24 hours before the matches, when the training program was composed of light exercises, and 40 hours after each match, when the subjects did not perform physical exercises.

\section{Incremental test}

The participants started the test running for $3 \mathrm{~min}$ utes at $6 \mathrm{~km} \cdot \mathrm{h}^{-1}$ for warm-up. Then, the test began at $8 \mathrm{~km} \cdot \mathrm{h}^{-1}$ and fixed inclination of $1 \%$ and $1 \mathrm{~km} \cdot \mathrm{h}^{-1}$ were incremented every minute until exhaustion. $\mathrm{VO}_{2}$ was continuously recorded with the use of open circuit spirometry (Metalyzer 3B, Cortex, Leipzig, Germany). The mean of the previous 30 seconds was calculated for each stage for the $\mathrm{VO}_{2}$. Besides, minute ventilation (VE) and carbon dioxide production $\left(\mathrm{VCO}_{2}\right)$ were measured. The respiratory exchange ratio was determined as $\mathrm{VCO}_{2} / \mathrm{VO}_{2}$ in the same time interval. HR was recorded during the last 10 seconds of each stage with a HR monitor (Polar S810i, Kempele, Finland). $\mathrm{VO}_{2 \max }$, in accordance with the American College of Sports Medicine [20], was obtained following the satisfaction of the established criteria: (1) plateau in $\mathrm{VO}_{2}$ with increased effort intensity; (2) respiratory quotient above 1.15; (3) HR in the previous stage \pm 10 beats $\cdot \mathrm{min}^{-1}$ in relation to the maximal HR predicted by age (220 age); (4) signs of extreme physical fatigue. VT was identified by an increase in the $\mathrm{VE} / \mathrm{VO}_{2}$ ratio without a concomitant increase of $\mathrm{VE} / \mathrm{VCO}_{2}$ with the consideration of the breakpoint in the $\mathrm{VCO}_{2}-\mathrm{VO}_{2}$ relationship. The $\mathrm{HR}$ and velocity at VT were also determined. 


\section{Internal load}

At the end of each match, the time duration (minutes) was registered and, 30 minutes later, the session RPE was obtained by the Borg CR-10 Scale adapted by Foster et al. [4]. It is a 10-point scale, and for each stimulus, a specific response is expected. Athletes were instructed to point at the value corresponding to the global intensity of the match: rest (0); very, very easy (1); easy (2); moderate (3); somewhat hard (4); hard (5 and 6); very hard (7, 8, and 9), or maximal (10). On this basis, it was possible to calculate the internal load of each match and the strain caused by the 5 games with the model proposed by Foster [3]. The internal load of each match was calculated by multiplying the session RPE score and the match duration. The analysis of monotony was performed by dividing the mean internal load by the standard deviation of the 5 matches. The strain was calculated as the ratio between the sum of the 5 matches and the monotony.

\section{Perceived recovery and perceived}

muscle soreness

PR was measured with the Perceived Recovery Scale modified from the Borg (1982) CR-10 Scale, with the initial descriptor 'fully recovered' (0) and final 'extremely tired' (10). PMS was indicated with the pain Visual Analogue Scale (VAS) [14], which illustrates pain as a continuous line where the initial value is always attributed to 'no pain' and the final value refers to 'unbearable pain.'

\section{Creatine kinase}

Serum blood samples of $3 \mathrm{ml}$ were collected from the antecubital vein of the dominant arm with the participants seated. The samples were deposited in heparinized test tubes (Laborglas, São Paulo, Brazil) and then analysed with a kit of reactive strips (Reflotron ${ }^{\circledast}$ Plus, Basel Schweiz, Switzerland) with the use of the reflectance photometry method [12].

\section{Quick Recovery Test}

The method for the recovery analysis uses the Firstbeat software (Firstbeat Pro 4.7.3.1, Jyväskylä, Finland) and is based on the analysis of the HR variability. The method reflects the state of the nervous system, which combines stress from different sources [21]. In principle, this method recognizes reactions of stress and recovery of the body through the intensity of the sympathetic and parasympathetic nervous system activation. The athletes placed the transmitting straps in the chest region and remained in low light and quiet environment, lying down for 3 minutes for the software to be triggered and to effectively start the collection, which lasted 5 minutes. The result of the recovery level based on the HR variability is presented in percentages.

\section{Statistical analyses}

Descriptive statistics were calculated and data were expressed by mean \pm standard deviation. Initially, normality was tested with the Shapiro-Wilk's test. Then, to verify the simple effect of the 5 matches on the session RPE, PR, PMS, QRT, and internal load, the repeated measures ANOVA was used. If the sphericity between the participants were violated in accordance with Mauchly's test, a Greenhouse-Geisser correction factor would be applied to correct the freedom degrees. The Bonferroni post-hoc test was used to observe the statistical differences. For the CK analysis, the Friedman ANOVA was used, followed by the Wilcoxon test, once this data set did not meet normality. The Spearman correlation coefficient was calculated to evaluate the correlation between the internal load variables of the 5 matches, the mean of the recovery variables, and the physical fitness level. Significance was set at $p<0.05$. The Statistical Package for the Social Sciences (SPSS ${ }^{\circledR}$ ), version 20.0 for Windows (Chicago, USA) was used for all the analyses.

\section{Ethical approval}

The research related to human use has been complied with all the relevant national regulations and institutional policies, has followed the tenets of the Declaration of Helsinki, and has been approved by the Ethics Committee from the Federal University of Paraná Health Sciences Department, under register No. 0081.0.091.000-08.

\section{Informed consent}

Informed consent has been obtained from all individuals included in this study.

\section{Results}

VT was identified in all the participants; HR and velocity at VT were $175 \pm 9$ beats $\cdot \mathrm{min}^{-1}$ and $16 \pm$ $1.4 \mathrm{~km} \cdot \mathrm{h}^{-1}$, respectively.

The quantification of the internal load is presented in Figure 1. No significant differences were found among the 5 matches $\left(f_{(4,10)}=0.86, p=0.49\right)$. The $95 \%$ 


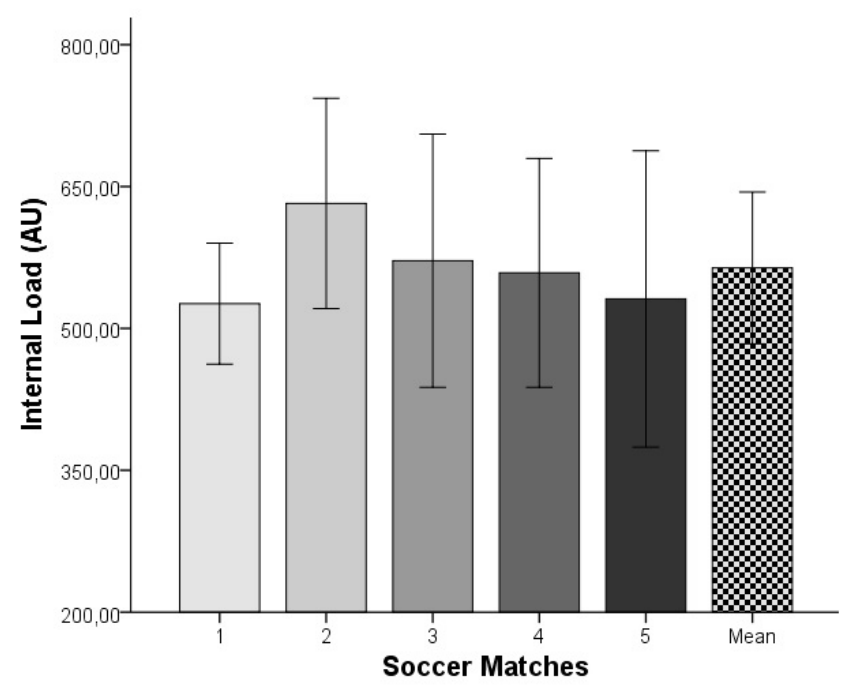

Figure 1. Internal load of the 5 consecutive soccer matches expressed by mean $\pm S D$

confidence intervals for the games were: game 1: 462590; game 2: 520-743; game 3: 437-705; game 4: 437679; game 5: 374-687. The strain presented the value of $11,619 \pm 3745 \mathrm{AU}$.

Neither did we observe significant differences for session $\operatorname{RPE}\left(f_{(4,10)}=0.76, p=0.55\right), \operatorname{PMS}\left(f_{(4,10)}=0.51\right.$, $p=0.73), \mathrm{CK}(p=0.24), \operatorname{QRT}\left(f_{(4,10)}=0.17, p=0.95\right)$, or $\operatorname{PR}\left(f_{(4,10)}=0.67, p=0.46\right)$ among the 5 consecutive matches $(p>0.05)$ (Table 1$)$.

Significant positive correlations were found between the mean session RPE vs. the HR at VT ( $\rho=0.62, p=$ 0.04; Figure 2A) and the mean session RPE vs. the mean internal load ( $\rho=0.92, p<0.001$; Figure $2 B$ ), mean internal load vs. mean CK $(\rho=0.63, p=0.04$; Figure 2C), and mean internal load vs. HR at VT ( $\rho=$ $0.66, p=0.027$; Figure 2D). Significant negative corre- lations were noted between the mean PR vs. the mean QRT ( $\rho=-0.62, p=0.04$; Figure $3 \mathrm{~A}$ ) and mean PR vs. matches strain $(\rho=-0.61, p=0.046$; Figure $3 \mathrm{~B})$. There were no correlations related to the velocity at VT or PMS $(p>0.05)$.

\section{Discussion}

The main objective of the present study was to investigate the internal load imposed by soccer matches and to determine whether it was related to the physical fitness and recovery status of professional soccer players during a competitive period. The hypothesis put forward was that the internal load remained stable between the matches and that it was correlated with the physical fitness and recovery status after the games. Thus, the main outcomes of the study were as follows: (1) a player's internal load was similar between consecutive matches; (2) it was positively correlated with HR at VT and serum CK concentration after the game; (3) unexpectedly, that the strain calculated from the internal load of the 5 games was negatively correlated with PR.

The quantification of the session internal load through RPE, proposed by Foster et al. [4], has been widely used by soccer clubs and considered a valid method for determining the load [5, 22]. In the present study, it was identified that the internal load of soccer matches during the beginning of the season did not differ between the games, which suggests that its behaviour was regular during the period (mean: 557.1 $\pm 116.4 \mathrm{AU}, p>0.05)$. These values are close to those observed by Impellizzeri et al. [5] (625 \pm 60 AU) after evaluating 12 young soccer players in 7 matches,

Table 1. Recovery variables 40 hours after each match (mean $+S D$ and 95\% confidence intervals)

\begin{tabular}{|c|c|c|c|c|c|c|}
\hline & \multicolumn{6}{|c|}{ Soccer matches } \\
\hline & 1 & 2 & 3 & 4 & 5 & Average \\
\hline Session RPE (score) & $\begin{array}{l}6.1 \pm 1.1 \\
(5.3-6.8)\end{array}$ & $\begin{array}{l}6.8 \pm 1.5 \\
(5.7-7.7)\end{array}$ & $\begin{array}{l}6.5 \pm 1.7 \\
(5.3-7.7)\end{array}$ & $\begin{array}{l}6.3 \pm 1.6 \\
(5.2-7.4)\end{array}$ & $\begin{array}{l}6.1 \pm 1.9 \\
(4.8-7.3)\end{array}$ & $6.4 \pm 1.2$ \\
\hline PR (score) & $\begin{array}{l}3.4 \pm 1.2 \\
(2.5-4.1)\end{array}$ & $\begin{array}{l}4.7 \pm 1.7 \\
(3.5-5.9)\end{array}$ & $\begin{array}{l}4.1 \pm 1.8 \\
(2.8-5.3)\end{array}$ & $\begin{array}{l}3.5 \pm 1.3 \\
(2.6-4.3)\end{array}$ & $\begin{array}{l}3.9 \pm 1.7 \\
(2.6-4.9)\end{array}$ & $3.9 \pm 1.2$ \\
\hline PMS (score) & $\begin{array}{l}0.9 \pm 1.2 \\
(0.9-3.5)\end{array}$ & $\begin{array}{c}2.5 \pm 2.1 \\
(1-3.9)\end{array}$ & $\begin{array}{l}2.8 \pm 2.8 \\
(0.9-4.6)\end{array}$ & $\begin{array}{l}1.8 \pm 2.1 \\
(0.4-3.2)\end{array}$ & $\begin{array}{l}3.1 \pm 2.5 \\
(1.4-4.8)\end{array}$ & $2.5 \pm 1$ \\
\hline $\mathrm{CK}\left(\mathrm{U} \cdot \mathrm{L}^{-1}\right)$ & $\begin{array}{l}689 \pm 442 \\
(392-986)\end{array}$ & $\begin{array}{l}636 \pm 328 \\
(415-857)\end{array}$ & $\begin{array}{c}633 \pm 582 \\
(241-1024)\end{array}$ & $\begin{array}{l}469 \pm 327 \\
(249-689)\end{array}$ & $\begin{array}{l}555 \pm 241 \\
(393-717)\end{array}$ & $596 \pm 321$ \\
\hline QRT (\%) & $\begin{array}{c}58.7 \pm 31.5 \\
(37.5-80)\end{array}$ & $\begin{array}{c}58.4 \pm 34 \\
(35.5-81.1)\end{array}$ & $\begin{array}{c}50.6 \pm 31.3 \\
(29.7-71.7)\end{array}$ & $\begin{array}{l}53.5 \pm 25.7 \\
(36.5-70.5)\end{array}$ & $\begin{array}{l}52.2 \pm 34.9 \\
(28.7-75.6)\end{array}$ & $54.7 \pm 17$ \\
\hline
\end{tabular}

RPE - rating of perceived exertion, PR - perceived recovery, PMS - perceived muscle soreness, CK - creatine kinase, QRT - Quick Recovery Test 


\section{HUMAN MOVEMENT}

L.F. Novack, Internal load, physical fitness, and recovery in soccer
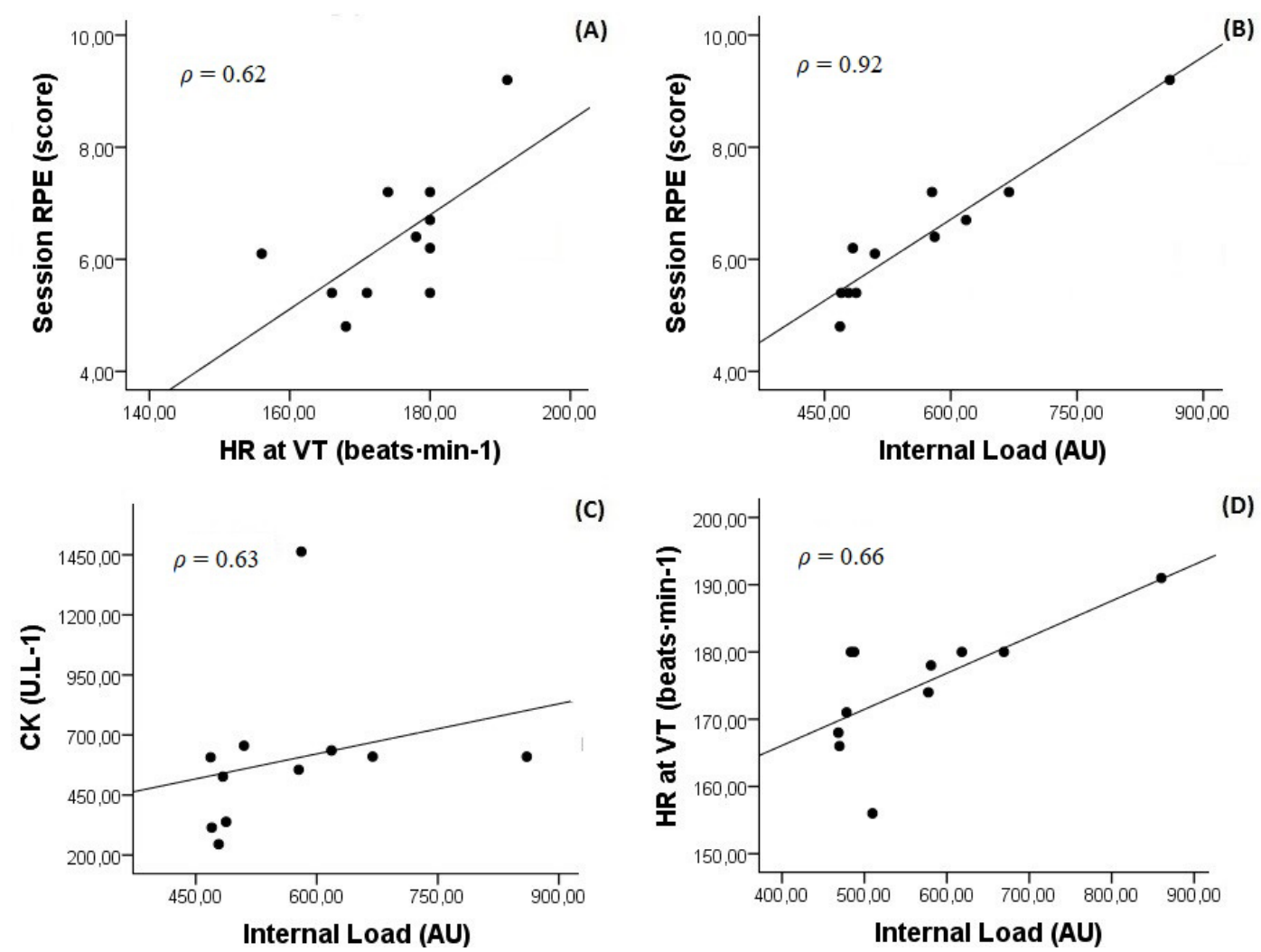

RPE - rating of perceived exertion, $\mathrm{HR}$ - heart rate, VT - ventilatory threshold, CK - creatine kinase

Figure 2. Positive correlations. (A) Session RPE $\times$ HR at VT. (B) Session RPE $\times$ internal load.

(C) CK concentration $\times$ internal load. (D) HR at VT $\times$ internal load
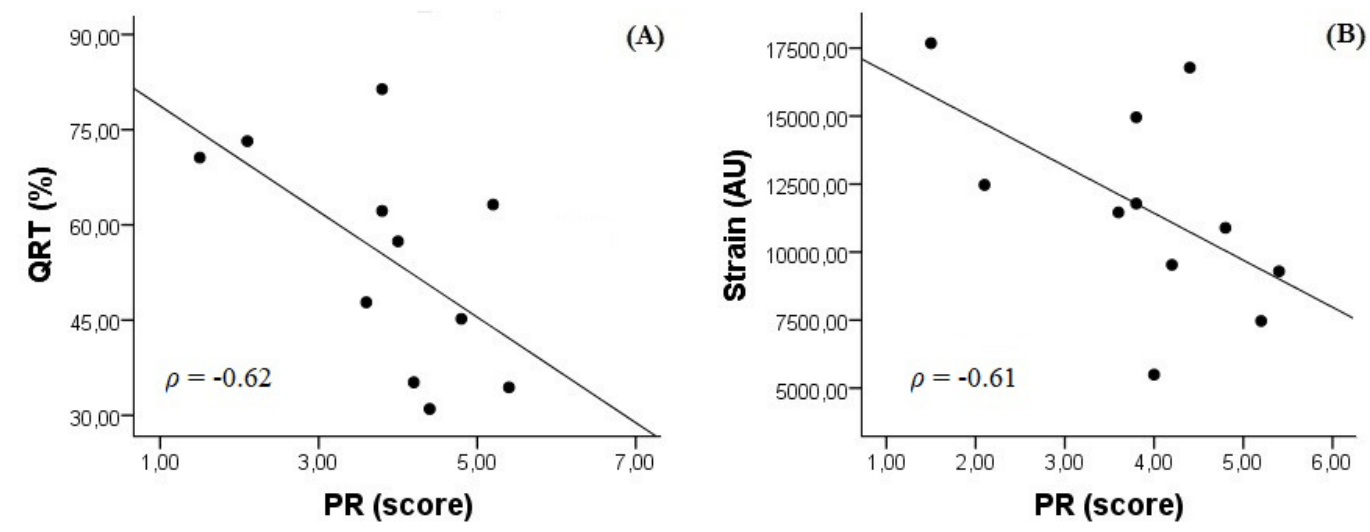

QRT - Quick Recovery Test, PR - perceived recovery

Figure 3. Negative correlations. (A) QTR $\times$ PR. (B) Strain $\times$ PR

in which they participated for at least 80 minutes. Session RPE is a good indicator for the evaluation of the training load during a season, once it has significant correlations with models that use HR to determine the training internal load $(r=0.50-0.85, p<0.01)$ [5]. However, quantification of the internal load in an official match has not been widely discussed, once the indicators of the external load (GPS systems and accelerometers), although still commonly used, do not provide information of the additional strain coming from several games. Previous studies with professional soccer athletes point that indicators of the relative external load have high correlation with the internal load obtained by the session RPE [23]. Thus, the game RPE is a useful strategy to quantify the match and to help with the training and recovery plan during the competitive period.

However, aerobic fitness of soccer athletes may influence their internal responses. It is known that the $\mathrm{VO}_{2}$ kinetics in an incremental test allows the deter- 
mination of the VT, which is an indicator of aerobic fitness and remains related to performance [24]. Manzi et al. [6] verified that, in elite soccer players, the VT determined by open circuit spirometry was correlated with the game metabolic power categories $(r=0.72$ $0.83, p<0.01$ ) during competitive seasons. Aslan et al. [25] also observed that blood lactate concentrations during an incremental test were associated with the distance covered during a game $(r=0.48-0.57, p<$ 0.05 ) and that young soccer players presented higher internal load during the first half compared with the second half, although the physiological strain was similar in both halves.

The results of the present study show significant correlations between HR at VT and game RPE and match internal load; however, no significant correlations were found with the velocity at VT (data not shown). Strong correlations have been demonstrated between the session RPE and the HR and the game internal load [2], owing to the contribution of anaerobic metabolism required by soccer $[25,26]$. Thus, the subjective method seems to reflect the internal changes in the athletes' organism, including their physical fitness level. In this study, correspondence analysis and $\mathrm{VO}_{2 \max }$ suggest that the sample represented elite professional soccer players and, indeed, the average physical fitness level was in line with that presented in the literature [6, 25], showing correlation with the match internal load.

Our results also demonstrate positive correlations between the match internal load and post-match serum CK concentrations, and inverse correlations between the QRT and the PR; however, no significant correlations were found in relation to the PMS. It means that the higher the match internal load, the higher the serum CK concentrations, which are associated with muscle damage and need an invasive method to be measured in soccer. Freitas et al. [11] identified that the $\mathrm{CK}$ and the total quality recovery (TQR) scale are sensible to changes in the training internal load in volleyball athletes. Osiecki et al. [12] observed inverse significant correlations between the TQR scale and post-match serum CK concentrations $(r=-0.75$, $p<0.05$ ), corroborating the present study. In addition, the correlation between the recovery markers was expected, since both represent the recovery status of the athletes. These markers (CK, PMS, PR, and QRT) are often used in soccer athletes for the evaluation of muscle damage and recovery because they are correlated with the wear caused by the game. A strong relationship has been demonstrated between the percentage of $\Delta \mathrm{CK}$ (final - baseline) and the displacement pattern in a simulated game [9]. A match causes a transient systemic imbalance that results in muscle damage and changes in performance-related inflammatory parameters [27]. Still, the lack of correlation with the PMS can be justified by the physical fitness level of the athletes, since studies have demonstrated that the pain threshold increases with high exposure to daily training-induced stress [28], as well as the decrease in serum CK concentration during and after recovery throughout the competitive year [29].

However, surprisingly, the strain calculated from the internal load of the 5 matches was inversely correlated to the PR. This unexpected result indicates that the higher the game-induced internal strain, the faster the recovery. Recently, Djaoui et al. [30], investigating the post-match fatigue kinetics in young and professional soccer players during a competitive period, observed that although the professionals presented higher fatigue after a game compared with the young players, they recovered faster owing to their increased physical fitness. Considering the findings of the present study, in which the physical fitness level was correlated to a higher match internal load, summed to the fact that a higher load generates higher internal strain [31], and consequently a more efficient recovery, it may be suggested that the physical fitness level is related to a better performance and recovery. That is, soccer players with better aerobic fitness weary more during matches, which causes higher stress to their body during the season, but also recover faster between games. It denotes that perceptive markers can be used to determine stress and recovery during the season as a training control to increase the physical fitness level and avoid overtraining.

It is important to recognize some limitations of the study. The first is the sample size $(n=11)$; however, our study was conducted in an official gaming environment, which limits the number of individuals that could participate. Another factor is the control of the training during the matches, since the training internal load between the games could clarify the influence of the training in the game. Nevertheless, this monitoring or intervention was not possible because the team participated in a high level official championship and was preparing for the $1^{\text {st }}$ division of the national league. Despite these limitations, the outcomes of the study are important and corroborate the current literature concerning physical fitness [6, 25], game performance [5, 26], and recovery in soccer athletes [9, 27, 30], allowing further discussion about the session RPE in soccer.

In summary, the response of the internal load between consecutive matches was similar, and remained 
related to the physical fitness and indirect markers of muscle damage (CK) after the game. Additionally, the strain calculated from the internal load of the 5 matches turned out inversely related to the recovery from the game. Together, these results suggest that soccer athletes with better aerobic fitness are able to weary more during the game, present higher strain during the season, but also recover faster between games.

\section{Disclosure statement}

No author has any financial interest or received any financial benefit from this research.

\section{Conflict of interest}

The authors state no conflict of interest.

\section{References}

1. Bangsbo J, Mohr M, Krustrup P. Physical and metabolic demands of training and match-play in the elite football player. J Sports Sci. 2006;24(7):665-674; doi: 10.1080/ 02640410500482529 .

2. Casamichana D, Castellano J, Calleja-Gonzalez J, San Román J, Castagna C. Relationship between indicators of training load in soccer players. J Strength Cond Res. 2013;27(2):369-374; doi:10.1519/JSC.0b013e3182548af1.

3. Foster C. Monitoring training in athletes with reference to overtraining syndrome. Med Sci Sports Exerc. 1998; 30(7):1164-1168; doi: 10.1097/00005768-19980700000023.

4. Foster C, Florhaug JA, Franklin J, Gottschall L, Hrovatin LA, Parker S, et al. A new approach to monitoring exercise training. J Strength Cond Res. 2001;15(1):109115; doi: 10.1519/00124278-200102000-00019.

5. Impellizzeri FM, Rampinini E, Coutts AJ, Sassi A, Marcora SM. Use of RPE-based training load in soccer. Med Sci Sports Exerc. 2004;36(6):1042-1047; doi: 10.1249/01.MSS.0000128199.23901.2F.

6. Manzi V, Impellizzeri F, Castagna C. Aerobic fitness ecological validity in elite soccer players: a metabolic power approach. J Strength Cond Res. 2014;28(4):914919; doi: 10.1519/JSC.0000000000000239.

7. Nédélec M, McCall A, Carling C, Legall F, Berthoin S, Dupont G. Recovery in soccer: part I - post-match fatigue and time course of recovery. Sports Med. 2012;42(12): 997-1015; doi: 10.2165/11635270-000000000-00000.

8. Kinugasa T, Kilding AE. A comparison of post-match recovery strategies in youth soccer players. J Strength Cond Res. 2009;23(5):1402-1407; doi: 10.1519/JSC. 0b013e3181a0226a.

9. Aquino RL, Gonçalves LG, Vieira LH, Oliveira LP, Alves GF, Santiago PR, et al. Biochemical, physical and tactical analysis of a simulated game in young soccer players. J Sports Med Phys Fitness. 2016;56(12):15541561.

10. Russell M, Northeast J, Atkinson G, Shearer DA, Sparkes W, Cook CJ, et al. Between-match variability of peak power output and creatine kinase responses to soccer match-play. J Strength Cond Res. 2015;29(8): 2079-2085; doi: 10.1519/JSC.0000000000000852.

11. Freitas VH, Nakamura FY, Miloski B, Samulski D, Bara-Filho MG. Sensitivity of physiological and psychological markers to training load intensification in volleyball players. J Sports Sci Med. 2014;13(3):571-579.

12. Osiecki R, Rubio TBG, Coelho RL, Novack LF, Conde JHS, Alves CG, et al. The Total Quality Recovery Scale (TQR) as a proxy for determining athletes' recovery state after a professional soccer match. J Exerc Physiol Online. 2015;18(3):27-32.

13. Laurent CM, Green JM, Bishop PA, Sjökvist J, Schumacker RE, Richardson MT, et al. A practical approach to monitoring recovery: development of a perceived recovery status scale. J Strength Cond Res. 2011;25(3): 620-628; doi: 10.1519/JSC.0b013e3181c69ec6.

14. Price DD, McGrath PA, Rafii A, Buckingham B. The validation of visual analogue scales as ratio scale measures for chronic and experimental pain. Pain. 1983;17(1):\} 45-56; doi: 10.1016/0304-3959(83)90126-4.

15. Ascensão A, Leite M, Rebelo AN, Magalhäes S, Magalhäes J. Effects of cold water immersion on the recovery of physical performance and muscle damage following a one-off soccer match. J Sports Sci. 2011;29(3):217225; doi: 10.1080/02640414.2010.526132.

16. Jones NS. Update: soccer injury and prevention, concussion, and chronic groin pain. Curr Sports Med Rep. 2014;13(5):319-325; doi: 10.1249/JSR.0000000000 000085.

17. Campos EZ, Bastos FN, Papoti M, Freitas Junior IF, Gobatto CA, Balikian Junior P. The effects of physical fitness and body composition on oxygen consumption and heart rate recovery after high-intensity exercise. Int J Sports Med. 2012;33(8):621-626; doi: 10.1055/ s-0031-1295442.

18. Short KR, Sedlock DA. Excess postexercise oxygen consumption and recovery rate in trained and untrained subjects. J Appl Physiol. 1997;83(1):153-159; doi: 10.1152/jappl.1997.83.1.153.

19. Jackson AS, Pollock ML. Generalized equations for predicting body density of men. Br J Nutr. 1978;40(3):497504; doi: 10.1079/BJN19780152.

20. American College of Sports Medicine. ACSM's guidelines for exercise testing and prescription. Philadelphia: Lippincott Williams \& Wilkins; 2013.

21. Nuuttila O-P, Nikander A, Polomoshnov D, Laukkanen JA, Häkkinen K. Effects of HRV-guided vs. predetermined block training on performance, HRV and serum hormones. Int J Sports Med. 2017;38(12):909920; doi: 10.1055/s-0043-115122.

22. Akubat I, Patel E, Barrett S, Abt G. Methods of monitoring the training and match load and their relationship to changes in fitness in professional youth soccer players. J Sports Sci. 2012;30(14):1473-1480; doi: 10.1080/02640414.2012.712711.

23. Scott BR, Lockie RG, Knight TJ, Clark AC, Janse de Jonge XAK. A comparison of methods to quantify the 
in-season training load of professional soccer players. Int J Sports Physiol Perform. 2013;8(2):195-202; doi: 10.1123/ijspp.8.2.195.

24. Burnley M, Jones AM. Oxygen uptake kinetics as a determinant of sports performance. Eur J Sport Sci. 2007;7(2):63-79; doi: 10.1080/17461390701456148.

25. Aslan A, Acikada C, Güvenç A, Gören H, Hazir T, Özkara A. Metabolic demands of match performance in young soccer players. J Sports SciMed. 2012;11(1):170179.

26. Stølen T, Chamari K, Castagna C, Wisløff U. Physiology of soccer: an update. Sports Med. 2005;35(6):501536; doi: 10.2165/00007256-200535060-00004.

27. Romagnoli M, Sanchis-Gomar F, Alis R, Risso-Ballester J, Bosio A, Graziani RL, et al. Changes in muscle damage, inflammation, and fatigue-related parameters in young elite soccer players after a match. J Sports Med Phys Fitness. 2016;56(10):1198-1205.

28. Geva N, Defrin R. Enhanced pain modulation among triathletes: a possible explanation for their exceptional capabilities. Pain. 2013;154(11):2317-2323; doi: 10.1016/j.pain.2013.06.031.

29. Silva JR, Rebelo A, Marques F, Pereira L, Seabra A, Ascensão A, et al. Biochemical impact of soccer: an analysis of hormonal, muscle damage, and redox markers during the season. Appl Physiol Nutr Metab. 2014;39(4): 432-438; doi: 10.1139/apnm-2013-0180.

30. Djaoui L, Garcia JD-C, Hautier C, Dellal A. Kinetic postmatch fatigue in professional and youth soccer players during the competitive period. Asian J Sports Med. 2016;7(1):e28267; doi: 10.5812/asjsm.28267.

31. Nakamura FY, Moreira A, Aoki MS. Training load monitoring: is the session rating of perceived exertion a reliable method? [in Portuguese]. Rev Educ Fis. 2010;21(1): 1-11; doi: 10.4025/reveducfis.v21i1.6713. 